Las Torres de Lucca. Revista internacional de filosofía política

ISSN-e: 2255-3827

\title{
Populismo, (post) hegemonía y democracia: repensar el populismo sin hegemonía ${ }^{1}$ \\ David Alejandro Valencia Gutierrez ${ }^{2}$
}

Recibido: 5-4-2021 / Aceptado: 30-8-2021 / Publicado: 30-01-2022

Resumen. El presente artículo plantea que el uso de la noción de hegemonía en la argumentación sobre el populismo y su capacidad democratizante en la obra de Ernesto Laclau implica un rezago antidemocrático que resta potencial emancipador y de ampliación de la participación política. La argumentación de Laclau incluye como horizonte ineludible de la articulación de un movimiento populista la formación de una hegemonía que sea capaz de disputar el poder político y que configure una cadena de equivalencias entre demandas sociales insatisfechas. En consecuencia, el presente artículo revisa dos frentes de crítica a la argumentación de Laclau sobre la hegemonía en el populismo: uno que proviene de la academia estadounidense y es liderado por Alberto Moreiras, otro que viene de la sociología argentina con la que interactuó Laclau: Gerardo Aboy Carlés y Emilio de Ípola. El sentido de revisar estas críticas es repensar el populismo sin hegemonía para hallar un camino que supere las dificultades que desde distintos frentes se atribuyen a la obra de Laclau. En la estela de los y las autoras que han avanzado del populismo de Laclau al populismo republicano, en diferentes versiones de combinación, la hipótesis que se defenderá en adelante es que cualquier transición del populismo a un escenario democrático requiere desprenderse de la idea de hegemonía y por tanto, el populismo se puede recategorizar en torno a su capacidad de dar solución a demandas insatisfechas y ampliar la participación política institucional, en lo que llamaré populismo transformativo.

Palabras clave: populismo transformativo; democratización; posthegemonía; demandas sociales insatisfechas.

\section{[en] Populism, (post) hegemony and democracy: rethinking populism without hegemony}

\begin{abstract}
This article proposes that the use of the notion of hegemony in the argument about populism and its democratizing capacity in Ernesto Laclau's work implies an undemocratic lag that subtracts the potential for emancipation and expansion of political participation. Laclau's argumentation includes as an inescapable horizon of the articulation of a populist movement the formation of a hegemony that is capable of contesting political power and that configures a chain of equivalences between unsatisfied social demands. Consequently, this article reviews two fronts of criticism of Laclau s argument about hegemony in populism: one that comes from the American academy and is led by Alberto Moreiras and another that comes from Argentine sociology with which Laclau interacted: Gerardo Aboy Carlés and Emilio de Ípola. The sense of reviewing these criticisms is to rethink populism without hegemony to find a way that overcomes the difficulties that from different fronts are attached to Laclau's work. In the wake of the authors who have advanced from Laclau populism to republican populism, in different versions of combination, the hypothesis that will be defended from now on is that any transition from populism to a democratic scenario requires detaching from the idea of hegemony and therefore, populism can be re-categorized around its ability to solve unsatisfied demands and broaden institutional political participation, in what I will call transformative populism.
\end{abstract}

Keywords: transformative populism; democratization; posthegemony; unsatisfied social demands.

Cómo citar: Valencia Gutierrez, D. A. (2022). Populismo, (post) hegemonía y democracia: repensar el populismo sin hegemonía. Las Torres de Lucca. Revista internacional de filosofia politica, 11(1), 65-78. https://dx.doi.org/10.5209/1tdl.77040

El populismo se ha reinstalado en las discusiones políticas contemporáneas como una categoría central. La academia interesada en el desarrollo del concepto ha revitalizado la discusión a partir de una lectura crítica del presente que pudo calificarse como momento populista una vez que Donald Trump triunfó en las elecciones presidenciales de Estados Unidos en 2016. Desde ese momento, el temor y la discusión sobre el populismo han estado en constante crecimiento. En este escenario, el presente texto pretende establecer una nueva clasificación del populismo que supere, hasta cierto punto, la distinción izquierda-derecha para dar paso a la

Este artículo fue posible gracias a la financiación del proyecto C120-387 de la convocatoria interna de investigación de Uniminuto. Agradezco los comentarios atentos de los profesores Delfín Ignacio Grueso, de la Universidad del Valle; Alberto Moreiras, de la Universidad de Texas a\&m y al profesor José Luis Moreno Pestaña, de la Universidad de Granada. Agradezco también la atenta revisión y críticas constructivas de los o las evaluadoras de este artículo que contribuyeron sin duda alguna para la cualificación de la versión final.

2 David Alejandro Valencia Gutierrez, Departamento de Educación, Corporación Universitaria Minuto de Dios- Uniminuto.

Correo electrónico: david.valencia@uniminuto.edu.co

ORCID: https://orcid.org/0000-0002-8277-5306

Las Torres de Lucca. 11 (1), 2022: 65-78 
distinción afirmación-transformación que, anclada en la teoría de Ernesto Laclau, sirva para corregir o superar problemas teóricos que dificultan el uso del populismo en proyectos emancipatorios.

Aunque el populismo como tradición académica tiene una trayectoria de algo más de 150 años, en las últimas décadas ha estado asociado, casi confundido, con la obra de un solo pensador, Ernesto Laclau. La obra de Laclau ha tenido un impacto considerable en movimientos políticos, especialmente de izquierda, en la conocida marea rosa y más recientemente en la latinoamericanización de la política europea liderada por Podemos, el joven partido político español. Indiscutiblemente, Laclau tuvo un papel central en el desarrollo del pensamiento político de los populismos radicales de principios de siglo XXI en Sudamérica, pero la deriva de estos proyectos ha puesto en cuestión la obra misma de este pensador. Hoy el escenario político es otro y el populismo, aún potente, pareciera beneficiar más a los movimientos de la derecha alternativa que a la izquierda populista surgida en la última década.

No obstante, contra la teoría populista de Laclau se alzan por lo menos dos críticas importantes. Primero, que su rechazo a las lógicas diferenciales es también un rechazo a cualquier institucionalidad democrática que sirva para responder a las demandas sociales. Segundo, que su cuasi identificación entre política, populismo y hegemonía limita cualquier potencial demócrata radical en su propuesta, puesto que supone que la superación de una hegemonía puede darse a través de otra que, en todo caso, implica la dominación de una clase o grupo sobre otros.

Una alternativa que supere estas dos falencias, aun siendo populista, supondría que es posible un populismo que fortalezca las instituciones políticas para resolver las demandas sociales aún en desmedro de la preservación de su base social. Hasta ahora, las salidas teóricas a este problema han complementado la posición populista de Laclau con una transición a versiones democráticas del republicanismo. Encontramos en los trabajos de Luciana Cadahia y Valeria Coronel (2018), José Luis Villacañas (2017) y de Carlos Fernández Liria (2016) salidas en el sentido antes mencionado que, aunque con matices no problematizan el uso de la idea de hegemonía como impedimento en esa transición.

La hipótesis que se defenderá en adelante es que cualquier transición del populismo a un escenario republicano requiere desprenderse de la idea de hegemonía tal como es usada por Laclau en su teorización del populismo. Para concretar esta hipótesis, propongo una clasificación alternativa para el populismo pasando de la díada izquierdaderecha a afirmación-transformación para lo cual retomo la distinción que hace Nancy Fraser de las soluciones a la injusticia social en relación con el concepto de posthegemonía desarrollado por Alberto Moreiras.

De acuerdo con lo mencionado, estructuraré el resto del documento así: en primer lugar, se presentarán los elementos básicos de la teoría populista de Laclau. En segundo lugar, se evaluarán las falencias en la teoría de Laclau, especialmente, su uso de la noción de hegemonía y la falta de una teoría de la institucionalización de las transformaciones populistas para la democratización y ampliación de la participación política. Finalmente, se presenta la distinción afirmación-transformación que anclada en la idea de posthegemonía provee un escenario nuevo para pensar el populismo como un camino a la ampliación de la participación política de los y las históricamente excluidos a través del republicanismo plebeyo.

Por su parte, la autora argentina María Julia Bertomeu (2005) delimita la diferencia entre las vertientes republicanas en la filosofía en función de su apertura democrática y el fortalecimiento de la participación política. Así, encuentra que el republicanismo ha tenido dos versiones que se remontan a la antigua Grecia. Su clasificación es la siguiente:

El republicanismo es una tradición milenaria, bien arraigada en el mediterráneo antiguo clásico, y común y justamente asociada a los nombres de Ephialtes, Pericles, Protágoras o Demócrito (en su versión democráticoplebeya) y a los de Aristóteles o Cicerón (en su versión antidemocrática). En el mundo moderno, reaparece también en sus dos variantes: la democrática, que aspira a la universalización de la libertad republicana y a la consiguiente inclusión ciudadana de la mayoría pobre, y aun al gobierno de esa mayoría de pobres-; y la antidemocrática, que aspira a la exclusión de la vida civil y política de quienes viven por sus manos, y al monopolio del poder político por parte de los ricos propietarios; (Bertomeu, 2005, p. 2).

Esa clasificación es importante porque la versión (neo)liberal del republicanismo ha asumido una posición altamente antidemocrática al pasar la dirección del Estado a los tecnócratas y aislar a las personas de las decisiones democráticas convirtiendo ciudadanos en consumidores que votan cada tanto para elegir al mejor tecnócrata con el objetivo único de ampliar la libertad negativa. Por su parte, el republicanismo democrático promueve la libertad como no-dominación sin importar diferencias para la participación en las decisiones políticas, es decir, una repolitización de la sociedad a través de garantías republicanas.

\section{El populismo en clave de Laclau}

El desarrollo del concepto de populismo en Ernesto Laclau es un proceso rastreable hasta sus textos tempranos de los años setenta. No obstante, la consolidación de ese proyecto teórico alcanzó su culmen en el ya clásico 
libro La razón populista (2009) y en algunos textos aclaratorios como "Populismo ¿Qué nos dice el nombre?" (2009b). Empero, esta presentación no será cronológica, sino que seguirá un orden categorial que nos permita acercarnos a los conceptos centrales de la obra y facilitará la comprensión de la forma como se articulan estos para ofrecer una de las teorías más iluminadoras sobre el populismo.

Laclau inicia su descripción del populismo estableciendo una distinción entre el uso común del concepto que es normalmente asignado a ideologías o partidos y un uso técnico que solo puede predicarse sobre cierta lógica de articulación de las demandas sociales para crear la identidad del pueblo (Laclau, 2009b). Es decir, el populismo laclausiano no constituye la ideología de un grupo social específico sino que es una cualidad adjudicable a movimientos sociales o partidos políticos que adquieren una forma hegemónica de articulación de las demandas sociales insatisfechas, intentando desde la particularidad, asumir la representación universal del pueblo como un todo. Laclau ofrece tres orientaciones teóricas para comprender, entonces, qué es y cómo funciona el populismo:

1) que el pensar la especificidad del populismo requiere comenzar el análisis a partir de unidades más pequeñas que el grupo (ya sea en el nivel político o en el ideológico); 2) que el populismo es una categoría ontológica y no óntica -es decir, su significado no debe hallarse en ningún contenido político o ideológico que entraría en la descripción de las prácticas de cualquier grupo específico, sino en un determinado modo de articulación de esos contenidos sociales, políticos o ideológicos, cualesquiera ellos fueran; 3) que la forma de articulación, aparte de sus contenidos, introduce efectos estructurantes que se manifiestan principalmente en el nivel de los modos de representación (Laclau, 2009b, p. 53).

Mi presentación mostrará cómo las categorías fundamentales del populismo y sus interconexiones demuestran en la lógica de Laclau estos tres elementos.

Pensar en unidades de análisis infragrupales podría dirigir nuestra atención al individuo, pero estaríamos perdidos. Por el contrario, Laclau se decanta por una categoría tal que tenga un alcance más limitado que la identidad de grupo pero que al tiempo conserve el espíritu de colectividad que da origen al colectivo político, esta categoría es la de "demanda social insatisfecha". Usamos el ejemplo del grupo pueblo, el colectivo por excelencia del populismo, para comprender por qué el análisis no podría partir de una colectividad social dada:

Una primera decisión teórica es concebir al "pueblo" como una categoría política y no como un dato de la estructura social. Esto significa que no designa a un grupo dado, sino a un acto de institución que crea un nuevo actor a partir de una pluralidad de elementos heterogéneos. Es por este motivo que insistimos desde el comienzo en que nuestra unidad de análisis mínima no sería el grupo, como referente, sino la demanda sociopolítica. Esto explica por qué preguntas tales como “¿de qué grupo social son expresión estas demandas?” no tienen sentido en nuestro análisis, dado que, para nosotros, la unidad del grupo es simplemente el resultado de una sumatoria de demandas sociales -que, por supuesto, pueden haber cristalizado en prácticas sociales sedimentadas-(Laclau, 2009, p. 278).

Aquí, Laclau presenta los elementos fundantes de su teoría tanto populista como hegemónica. En primer lugar, él no pretende hacer una descripción sociológica de un grupo y sus prácticas o identidad particular, sino que entiende el colectivo como un concepto político y, por tanto, como el producto de la agrupación de personas con demandas sociales insatisfechas que guardan algún tipo de relación entre ellas. En esta perspectiva, no es el grupo anterior a la demanda social sino la demanda social anterior al grupo e incluso anterior a las prácticas sociales y culturales del mismo.

El concepto "demanda" tiene dos significados: petición y reivindicación. Laclau no toma posición por alguna acepción, sino que prefiere mantener una tensión interna en el significado, que bien podría decantarse en una acción institucional o democrática o, por el contrario, en una reivindicación de carácter populista. Cuando la demanda se expresa como petición en el engranaje de la institucionalidad estatal, configura una demanda democrática. Este tipo de demandas sociales tienen un alcance muy limitado que debe ser tramitado por el poder encargado, quien finalmente puede satisfacerla o no sin mayor repercusión social o política; estas demandas son constitutivas de lo que Laclau llama lógica diferencial en tanto responden a la diferencia y especificidad de las demandas impidiendo su articulación. Sin embargo, "si por alguna razón la variedad de demandas insatisfechas es muy grande, esa frustración múltiple va a desencadenar lógicas sociales muy diferentes" (Laclau, 2009b, p. 56). Es decir, cuando una demanda insatisfecha, digamos sobre transporte público, se une con otras que aun siendo diferentes se entrecruzan, se configurará una cadena de equivalencias. En una cadena de equivalencias, una demanda social, además de expresar su particularidad, denota también a todas las demandas insatisfechas y así configura al sujeto popular, el pueblo, es decir, al grupo de personas que comparten demandas insatisfechas.

A partir de esta lógica de equivalencias, se establece otro elemento central de la conceptualización del populismo: el antagonismo. Que las demandas se mantengan insatisfechas implica que existe un poder externo, generalmente estatal, que las mantiene así, porque no responde efectivamente a las mismas. Es decir, una 
cadena de equivalencias tiene como función dividir el campo social entre el sujeto popular y el otro, el afuera constitutivo. Sin embargo, al ampliar el sujeto popular, los vínculos de las demandas se hacen débiles separando las demandas unas de otras e impulsando una lógica diferencial que produciría la disolución de la cadena de equivalencias .

El proceso de creación de una identidad política, el pueblo, es solo posible, desde la perspectiva de Laclau, a través de la hegemonía. El uso definitivo de este concepto en la propuesta del populismo de Laclau está presente en La razón populista (2009) pero se desarrolló en diversos trabajos académicos que, a veces en solitario, a veces con Chantal Mouffe, se publicaron en los últimos treinta años del siglo XX. Entre estos documentos destaca Hegemonía y estrategia socialista (2004) publicado en 1985, donde se explora el concepto de hegemonía, rescatado de la obra de Gramsci, como elemento central de una política emancipatoria con capacidad de radicalizar la democracia. En esta versión, Laclau y Mouffe consideran que la hegemonía es la clave de la articulación de las fuerzas sociales para la creación del pueblo.

Laclau y Mouffe tienen una primera concepción de la hegemonía como una práctica articulatoria en un sistema abierto de relaciones diferenciales. Es decir, que estos autores no comprenden la sociedad como una serie de relaciones sociales y económicas materiales sino como un campo discursivo abierto donde muchos significantes se mantienen indeterminados e inconexos entre ellos. En una concepción del campo social como campo semántico abierto es donde se puede dar un proyecto hegemónico justamente porque este busca la determinación de estos para producir una nueva interpretación de la realidad social.

Consideran Laclau y Mouffe que una concepción lingüística de lo social es clave para actualizar el concepto de hegemonía. Como bien ha afirmado Chantal Mouffe, la hegemonía es una "práctica que produce sujetos" y no al contrario. Así, "los sujetos no pueden ser el origen de las relaciones sociales, ni siquiera en el sentido limitado de estar dotados de facultades que posibiliten una experiencia, ya que toda experiencia depende de condiciones discursivas de posibilidad precisas" (Laclau y Mouffe, 2004, p. 156). Por tanto, la hegemonía debe ser entendida como una aspiración por determinar, precariamente, el sentido de las condiciones discursivas o significantes flotantes para articular y producir sujetos.

Esta aspiración de determinación discursiva propia de la hegemonía implica un "operación por la cual una particularidad asume una significación universal inconmensurable consigo misma" (Laclau y Mouffe, 2004, p. 95). Por tanto, en la perspectiva de estos pensadores, la hegemonía se convierte en el acto fundacional de un nuevo sujeto colectivo determinado por una disposición discursiva que se ha hecho universal. Siguiendo la lectura de Retamozo (2011), el concepto de hegemonía como particularidad hecha universalidad tiene tres usos prácticos: primero, es una lógica de formación constitutiva de la sociedad; segundo, es una lógica política que en ocasiones pareciera hacerse sinónimo de esta; tercero, es una lógica de constitución de identidades políticas. En esta línea, la construcción del pueblo, como identidad política pero también como totalidad de la sociedad, se da después de la instauración hegemónica y no antes, pues este pueblo solo podrá ser comprendido a partir de las nuevas relaciones entre significantes y significados que ha impulsado la formación hegemónica.

Como el discurso moldea la realidad, quien logre determinar el campo semántico, dominará los significados políticos y, en consecuencia, el poder político a partir de su propio entendimiento discursivo. Así, las clases subalternas no tendrían más opción que usar la misma universalidad semántica hegemónica que se ha instaurado facilitando el consenso de los subalternos respecto a la dirección política de los dominantes. Justamente, este proceso discursivo político se da porque a diferencia de "una alianza política circunstancial, que deja intacta la identidad de los conglomerados que participan en ella, la hegemonía modifica la identidad de las fuerzas intervinientes a través de valores e ideas compartidos que les permiten configurar un bloque histórico" (Arditi, 2011, p. 3).

En La razón populista (2009) Laclau, ahora en solitario, reutiliza el concepto de hegemonía en la lógica de expansión populista. El populismo empieza aquí a ser entendido como una lógica de articulación política que implica una lucha por los significados del campo semántico de lo social. Como menciona Benjamín Arditi (2011), en ocasiones Laclau genera una equivalencia entre política, populismo y hegemonía, aunque mantenga una diferencia de orden entre las dos últimas:

La diferencia específica que introduce el populismo vis-à-vis la hegemonía es la división de la sociedad en dos campos con la finalidad de producir una relación de equivalencia entre demandas y construir una frontera o relación antagónica entre ellas. Esta es la razón por la que se puede decir que el populismo es una especie del género hegemonía, la especie que cuestiona el orden existente con el propósito de construir otro orden (RP, 156-167). La otra especie es el anverso de la anterior: es el discurso institucionalista cuya esencia es mantener el statu quo y funciona como el blanco de la política populista (Arditi, 2011, p. 9).

La hegemonía es una particularidad que se ha convertido en universalidad en un campo semántico (social) determinando el sentido de los significantes flotantes. El populismo, entonces, usa la hegemonía de dos formas, como proyecto de resignificación de lo social y fundación de una nueva identidad política (plebs convertida en populus) y también, como blanco de tiro, en el caso de las hegemonías dominantes, para marcar el antagonismo entre el pueblo y el no pueblo. En consecuencia, el populismo de Laclau requiere de la hegemonía para ser 
tal, tomar el poder y establecer un consenso sobre los significantes flotantes a partir de la creación de nuevas identidades políticas.

No obstante, ni hegemonía ni populismo, pueden sin más, construir un pueblo, pues el proceso de vaciamiento de las demandas necesario para la construcción de la cadena de equivalencias diluye las posibilidades de encuentro y unión de estas. En términos del mismo autor, existe una tensión irresoluble entre la lógica diferencial y la lógica equivalencial en una misma demanda social. No obstante, el populismo privilegia la lógica equivalencial sobre la diferencial, sin que esta última desaparezca para operativizar el acto hegemónico de producción de identidad política. Así:

Cualquier identidad popular requiere ser condensada, como sabemos, en torno a algunos significantes (palabras, imágenes) que se refieren a la cadena equivalencial como totalidad. [...] Es decir, a la función de representar la cadena va a prevalecer sobre la de expresar el reclamo particular que constituye el material que sostiene esta función (Laclau, 2009, p. 125).

Por tanto, es indispensable en la consolidación hegemónica de un proyecto populista suplir esa necesidad de representación abstracta casi vacía de la cadena de equivalencias. La forma en que Laclau aborda esta cuestión es a través de una forma particular de entendimiento de la representación política:

Ahora bien, hay una característica de este proceso de construcción de una significación popular universal que reviste particular importancia para la comprensión del populismo. Es la siguiente: cuanto más se extiende la cadena de equivalencias, más débil será la conexión de las demandas particulares que asumen la función de representación universal con su particularismo inicial. Esto nos lleva a una conclusión que es central para nuestro análisis: la construcción de una subjetividad popular es posible sólo sobre la base de la producción discursiva de significantes tendencialmente vacíos. La denominada "pobreza" de los símbolos populistas es la condición de su eficacia política como su función es brindar homogeneidad equivalencial a una realidad altamente heterogénea, sólo pueden hacerlo sobre la base de reducir al mínimo su contenido particular. En su expresión más extrema, este proceso llega a un punto en que la función homogeneizante es llevada a cabo por un nombre propio: el nombre del líder. (Laclau, 2009b, p. 60)

Así, en la perspectiva de Laclau, el nombre del líder populista se convierte en la representación de la totalidad de la cadena de equivalencias, aun cuando este represente efectivamente una parte. Sin embargo, no es el líder como individuo mismo quien puede representar la cadena de equivalencias sino la enunciación de su nombre en tanto se ha convertido en significante vacío de la cadena de equivalencias y por tanto puede contener la particularidad hecha universalidad que es el pueblo. En palabras de Laclau, en tanto que la "totalidad o universalidad encarnada es, como hemos visto, un objeto imposible, la identidad hegemónica pasa a ser algo del orden del significante vacío, transformando a su propia particularidad en el cuerpo que encarna una totalidad inalcanzable" (Laclau, 2009, p. 95).

Un significante vacío es, por obvio que parezca, un significante sin significado. Sin embargo, esto tienen una utilidad política fundamental para la teoría populista de Laclau. Para este autor, cuanto más amplio sea el sujeto popular, más necesario será diluir la particularidad de las demandas individuales y darle relieve a la cadena de equivalencias hasta alcanzar la "identidad puramente equivalencial de un espacio comunitario" (Laclau, 1996, p. 78). Así, el significante vacío configura el límite entre el sujeto popular y su contrario y aprovecha la dilución de las demandas insatisfechas locales para concentrarlas en el significante vacío como representación de la totalidad de la cadena equivalencial.

Es tal la centralidad de esta figura para Laclau, que la considera condición necesaria para la concreción de un movimiento populismo. Opina el autor que un grupo

tal que, mediante la organización, hubiera asumido todas las funciones del individuo y hubiera eliminado la necesidad de un líder se corresponde, casi punto por punto, con una sociedad totalmente gobernada por lo que hemos denominado lógica de la diferencia (Laclau, 2009, p. 109).

La lógica de la diferencia que se menciona aquí es aquella que tramita las demandas insatisfechas en su especificidad mediante el aparato institucional de una sociedad y, por tanto, la posibilidad de una articulación populista sería imposible. Así, demanda social, cadena de equivalencias, hegemonía y líder carismático, se convierten en los elementos esenciales para pensar el populismo en la obra de Laclau, pues a falta de alguno, la articulación necesaria para el populismo no sería posible.

Es necesario precisar ahora cómo la exposición hecha da cuenta de las orientaciones que ofrece Laclau para comprender qué es y cómo funciona el populismo. El primer punto está relacionado con la unidad mínima del populismo, la demanda. Como vimos, Laclau considera que las demandas sociales son los elementos estructurantes de una cadena de equivalencias que constituye, por asociación, el sujeto popular o pueblo. Respecto al segundo punto, referido a la naturaleza del populismo como lógica de articulación en sentido 
ontológico, es decir, como forma de articulación a través del discurso que instaura en los sujetos la interpretación del mundo, vimos cómo al anclarse en la hegemonía como acto productor de identidades políticas mediante los significantes vacíos y flotantes el populismo per se no implica un contenido ideológico-político u óntico. Finalmente, la tercera orientación dirigida a los modos de representación da cuenta de la necesidad del líder populista en tanto nombre, porque seguimos operando en el terreno ontológico, que traza la frontera social entre el pueblo y los otros. Esta necesidad surge de la formación misma de la cadena de equivalencias, pues cada demanda ha tenido que vaciarse de contenido para hacerse equivalente y requiere, para mantener la unidad de grupo, de una forma de representación semántica que se expresa en un significante vacío.

\section{Críticas al populismo de Laclau: hegemonía e instituciones.}

Aunque la obra de Laclau es rica en conceptos y desarrollos coherentes, no es ajena a los cuestionamientos. Por supuesto, al presentar un desarrollo sobre un concepto polémico y tan mal publicitado como el populismo, Laclau ha recibido críticas desde todos los frentes teórico-políticos. Las posturas liberales generalmente sitúan al populismo como antípoda de la democracia liberal y argumentan a favor de la última como es el caso de Osvaldo Guariglia (2011) o más recientemente el historiador Enrique Krauze en el libro El pueblo soy yo (2018). En los autores citados y en todas las críticas liberales al populismo existe una misma preocupación: el populismo amenaza las instituciones democráticas liberales y el equilibrio de poder dejando la dirección política en manos, generalmente, de líderes autoritarios y con dudosos métodos para el ejercicio político. Desde el marxismo, las críticas tampoco se han hecho esperar, aunque tienen un enfoque completamente diferente. El caso de Atilio Borón (2000) es uno de los mejores ejemplos de este tipo de críticas a Laclau pues en lugar de interesarse por la utilidad o el potencial emancipador del populismo, Borón cuestiona la forma como Laclau intenta mantener lazos con el marxismo, incluso después de defender cierta forma de democracia liberal en Hegemonía y estrategia socialista.

Aunque, en general, el uso peyorativo de la palabra populismo se encuentra bastante lejano de la realidad, hay algo en lo que no se equivoca. El populismo, tal cual lo describe Laclau, es una antítesis de la institucionalidad demoliberal. En el origen mismo del análisis laclausiano sobre el populismo, en el concepto de demanda se presenta una ruptura tácita, pero radical con la institucionalidad democrática liberal, pues ante una demanda resuelta por el orden institucional no existe posibilidad alguna de articulación populista. Por lo anterior, Laclau traza una distinción entre su lógica, la equivalencia, y la lógica democrática o lógica de la diferencia: la primera permite la articulación populista mientras que la segunda permite el afianzamiento de un régimen político determinado.

El problema derivado de esta ruptura es doble: por un lado, rechaza la posibilidad de mitigación del sufrimiento y la injusticia vivida por los demandantes y por el otro, deja sin sustento teórico a lo que Luciana Cadahia (2019) llama una institucionalidad populista, es decir, una salida para la solución de las demandas que originaron al movimiento populista en primer lugar. El rechazo de Laclau a la institucionalidad (2009b) se profundiza cuando afirma que "las lógicas sociales que operan de acuerdo con este modelo diferencial e institucionalizado las denominaremos lógicas de la diferencia. Ellas presuponen que no hay división social y que toda demanda legítima puede satisfacerse de un modo administrativo, no antagónico" (p. 56). En otras palabras, Laclau considera que la institucionalidad que tramita una demanda social y la satisface afianza aquello que Mouffe llama la pospolítica, el escenario opuesto a la conflictividad populista.

Frente a este posicionamiento de Laclau, encontramos dos críticas brillantes y particularmente articuladas. Francisco Panizza (2008) y Gerardo Aboy Carlés (2010) discuten la relación entre populismo e institucionalidad democrática y plantean una visión crítica frente a la dislocación esencialista que pretende Laclau al rechazar dicha institucionalidad.

En un marco más amplio de crítica se encuentra Panizza, quien se pregunta por las fisuras entre populismo y democracia derivadas de la forma de representación del populismo laclausiano, que aspira a la conversión de la plebs en el populus o demos. Es decir, Panizza encuentra la fisura como el resultado del acto hegemónico por el cual una parte de la sociedad aspira a representar a la totalidad sin representarla efectivamente. Veamos su análisis:

En el discurso populista, un nuevo orden constitucional es necesario para superar la tensión entre el momento de ruptura -que, si fuera reproducido en el tiempo, conduciría a una política de revolución permanente- y la integración al orden institucional existente -que, de completarse, marcaría el fin del populismo-. Una asamblea constituyente representa el momento de ruptura radical que significa el ejercicio inmediato de la soberanía por parte del pueblo: como miembros de la asamblea, quienes integran la plebe pueden aspirar a convertirse en el demos. La autoridad política del pueblo es legitimada por la investidura radical del poder soberano en la asamblea constituyente, liberada de cualquier otra fuente de autoridad: con esta base, el pueblo, como portador de la soberanía, no sólo tiene el derecho de decidir las reglas para tomar decisiones en la asamblea, sino 
también para determinar las reglas del nuevo orden político sin considerar ningún precedente ni convención (Panizza, 2008, p. 89).

Aquí, Panizza pone en relieve las implicaciones para un sistema democrático de la llegada de un populismo al poder. El movimiento populista se presenta, por lo general, en tiempos de ruptura política o crisis orgánicas que requieren refundaciones institucionales de los sistemas políticos para crear nuevos consensos en torno a las instituciones. No obstante, el populismo necesitado de esos momentos de ruptura, generalmente asociados a asambleas constituyentes, debe resolver una tensión subyacente a la ruptura misma: mantener la asamblea en el tiempo o producir un marco institucional nuevo que resuelva las demandas sociales que originaron la ruptura en primer lugar. En ambos casos sobreviene el debilitamiento del movimiento populista y para un populista convencido como Laclau deberían ser evitados. La solución populista a esta tensión es la legitimación, antes política y ahora jurídica, del líder como representante de la totalidad social. En otras palabras, el uso de la hegemonía que Laclau asocia al populismo tendría como resultado práctico, en el caso más extremo, la reducción de la representatividad del Estado a una única persona.

El resultado de este proceso, anota Panizza, es una indiscutible fisura entre populismo y democracia especialmente debilitante para las instituciones democráticas-republicanas. Al final, el intento hegemónico de representación de la totalidad social es "una ilusión, porque ningún orden social puede existir sin un afuera constitutivo" (Panizza, 2008, p. 89). Así, Panizza muestra con claridad el problema que anuncié en la introducción, el problema del día después, o lo que es igual, la falta de teoría o la incompatibilidad de la teoría de Laclau con cualquier posible "institucionalidad populista" duradera.

La centralidad de este problema para el populismo es capital pues, aunque explica satisfactoriamente la conformación de un movimiento populista, no ofrece luz alguna sobre cómo el movimiento populista en el poder podría resolver alguna de las demandas que originaron la cadena de equivalencias o problema del día después. Panizza lo expresa así:

El énfasis en el momento de ruptura ignora las aspiraciones fundacionales del populismo. La alternativa entre la institucionalización o la continuidad con un signo ideológico distinto reduce el populismo al momento de la ruptura $\mathrm{y}$, como tal, no nos permite entender la transición del populismo como el movimiento en las calles que llega a convertirse en régimen oficial (Panizza, 2008, p. 86).

En esta misma dirección apunta la crítica de Gerardo Aboy Carlés. Este sociólogo argentino ataca directamente la argumentación de Laclau respecto a la ruptura populismo-institucionalidad pues considera que existe, así Laclau se empeñe en negarlo, cierto grado de institucionalidad en el adentro de la lógica equivalencial que es compatible con las dinámicas populistas. Aboy Carlés sugiere que Laclau ha mitificado el momento de ruptura populista al punto que solo considera verdaderamente populista la consolidación de la ruptura en el acto hegemónico de representación. No obstante, habría una omisión de Laclau en su análisis de las tensiones derivadas del antagonismo social en la formación de cadenas de equivalencias que tienden a resolverse en algún proceso de integración comunitaria por medios institucionales. Estas tensiones son resultado de la doble cara de la cadena de equivalencia entre su adentro y su afuera. Por eso Aboy Carlés afirma que

La equivalencia será precisamente la lógica de constitución de algún tipo de límite que separa una solidaridad de otra, mientras que la diferencia es el nombre de su consecuente reverso, el espacio interior de una solidaridad conformada en la comunión en una exclusión. Lo que es equivalencia o diferencia en cada caso será por tanto una función de la determinación de un cierto límite solidario que por algún motivo es considerado decisivo en una situación dada (Aboy Carlés, 2010, p. 25).

La negación de Laclau de cualquier forma de institucionalización democrática resultante del populismo o su rechazo explícito de la lógica de la diferencia, al menos en el interior mismo de la cadena de equivalencia, deja al populismo, como propuesta de acción política, maniatado para resolver cualquiera de las demandas constitutivas de su propio movimiento social. En la aspiración de la consolidación de la hegemonía a través del significante vacío o líder populista, Laclau no logra ver las necesidades de institucionalización democráticarepublicana que sirva para mediar la tensión entre los adversarios resultantes de la ruptura populista. Aboy Carlés, sostiene que, incluso desde la misma argumentación laclausiana se deduce está necesidad institucionalista así:

Si el populismo es una forma específica de negociar mediante inclusiones y exclusiones la tensión entre la representación de la parte y la representación del todo comunitario, es claro que aun desde la perspectiva de Laclau, el movimiento del cierre comunitario, de la representación de la comunidad en su conjunto, sería también un momento institucionalista, ya que en sus propios términos y como hemos citado anteriormente, "un discurso institucionalista es aquel que intenta hacer coincidir los límites de la formación discursiva con los límites de la comunidad" (Aboy Carlés, 2010, p. 35). 
Puede notarse aquí que la lógica institucionalista, entendida en términos laclausianos, comparte características con la hegemonía entendida como representación de la totalidad social por una de sus partes. No obstante, el resultado de la argumentación laclausiana nos deja en un escenario catastrófico para un posible actuar populista en el día después. El motivo de esto es que no habría un escenario institucionalista auténticamente populista más allá de la consolidación hegemónica, pero esto, antes que emancipador o democrático, es excluyente y antidemocrático. Excluyente en tanto la consolidación hegemónica deja afuera de la nueva institucionalidad a algunos sectores sociales que antes detentaban el poder y antidemocrático porque no logra el tránsito del pueblo (plebs), ahora en el poder, al demos como impulsor de las lógicas políticas. Así, el populismo fallaría en la construcción de lo común en un escenario de toma del poder. Por tanto, un populismo que priorice hegemonía frente a la renovación institucional carece de potencial emancipador y además profundiza los riesgos de la hegemonía como estrategia.

Hasta ahora no he ahondado en Laclau como un pensador de izquierda, sino que he intentado mostrarlo en su faceta no militante para revisar con mayores detalles sus conceptos en el nivel de la teoría política. No obstante, es preciso aclarar que Laclau suscribe un populismo de izquierda donde, siguiendo todos los elementos mencionados antes, se construya un pueblo con los de abajo para su emancipación. Esto implica, siguiendo la ontología vaciada del populismo, que la característica de la izquierda en un movimiento populista está determinada exclusivamente por el tipo de demandas sociales que lo fundamentan.

El compromiso político de Laclau fue inicialmente con la profundización de la democracia liberal a través de la estrategia hegemónica como puede evidenciarse en Hegemonía y estrategia socialista (2004). Sin embargo, La razón populista (2009) da cuenta de un Laclau que ya no guarda compromiso decidido con las demandas democráticas en la forma como se argumentaron antes, ni con la democracia liberal y su posible radicalización. En ambos casos, el compromiso con la izquierda del autor se hace desde la hegemonía misma, pues afirma que "la visión de Gramsci de hegemonía trasciende la distinción Estado/sociedad civil, pero es, sin embargo, profundamente democrática porque implica la introducción de nuevos sujetos colectivos en la arena histórica" (Laclau, 2009, p. 212).

La crítica al uso de la hegemonía en la obra de Laclau ha sido quizá la más abultada y diversa. Algunos críticos como Benjamín Arditi (2010) se inquietan por la indistinción entre populismo y hegemonía. Otros, desde una perspectiva marxista como Samuele Mazzolini (2020), han mostrado la inoperancia de la hegemonía laclausiana por ser un concepto vacío de contenido con una aparente falta de gramscianismo, es decir, por proponer una versión en la que las ideas originales de Gramsci se han simplificado demasiado. Y otros se han inquietado por la capacidad emancipadora de la hegemonía como concepto central del accionar populista, especialmente en un populismo de izquierda. Entre estos últimos, destaca la crítica del filósofo argentino Emilio de Ípola, que presentaremos a continuación.

Emilio de Ípola en un artículo ya clásico al interior de los estudios populistas "La última utopía" (2009), ha hecho una de las críticas más brillantes a la hegemonía presente en La razón populista (2009) de Laclau. La crítica es esencialmente una objeción al potencial democratizador o emancipador de la hegemonía en Gramsci y secundariamente en Laclau. El argumento de De Ípola es que el desarrollo de la hegemonía por Gramsci se hizo como una alternativa a la toma violenta del poder coercitivo del Estado, pues parecía que tal cosa no era viable en las sociedades desarrolladas europeas de principios del siglo XX. En todo caso, tanto la toma del poder coercitivo como la hegemonía, la toma de los espacios culturales para obtener la adhesión de las clases subalternas, tienen como fin último, para Gramsci, la instauración de la dictadura del proletariado; otro medio para el mismo fin.

El impacto de la hegemonía como estrategia de toma del poder muestra, según De Ípola, que Gramsci veía al marxismo como "un movimiento suprapolítico que se proyectaba a escala mundial como el heredero auténtico del mensaje de salvación universal del mesianismo cristiano" (Ípola, 2009, p. 218). Así, el marxismo no se limitaba a un movimiento político que se agotaba en la terminación de la explotación capitalista de la clase obrera sino una ciencia que podría redefinir por completo la forma de vida del planeta entero. Por supuesto, anota Ípola, una visión totalizadora del mundo tiene poco de democrática y el ejercicio de su expansión por la acción hegemónica tampoco, pues tiene como finalidad la creación de una identidad política universal que excluiría culturalmente a cualquier otra.

Como hace notar Î́pola, este rasgo totalizador se evidencia aún más con la centralidad que da Gramsci al Partido Comunista como "sujeto trascendente y providencial [...] al cual la historia le ha asignado la misión de transformar al hombre y la sociedad" (Ípola, 2009, p. 219). Entiende Gramsci que la hegemonía debe ser la estrategia a seguir por el partido comunista para lograr su objetivo trascendente; la emancipación. De Ípola trae una cita especialmente clara de Gramsci en este sentido:

El moderno Príncipe, desarrollándose, trastorna todo el sistema de relaciones intelectuales y morales en cuanto que su desarrollo significa precisamente que todo acto es concebido como útil o dañino, como virtuoso o perverso, sólo en cuanto que tiene como punto de referencia al moderno Príncipe mismo y sirve para incrementar su poder o para obstaculizarlo. El Príncipe toma el lugar, en las conciencias, de la divinidad o del imperativo 
categórico, se convierte en la base de un laicismo moderno y de una completa laicización de toda la vida y de todas las relaciones habituales (Gramsci como se citó en De Ípola, 2009, p. 218).

Vemos entonces cómo el príncipe moderno o el Partido comunista se convierte en el líder totalizante de una sociedad o incluso, según la visión mesiánica de Gramsci, del planeta entero y esto es posible a través de la dominación hegemónica. El problema para Laclau, afirma Ípola, es que al retomar el concepto hegemonía como elemento central del populismo hereda también su carga antidemocrática, pues una hegemonía efectiva tendería "a destruir todas las organizaciones o incorporarlas en un sistema donde el partido sea el único regulador" (De Ípola, 2009, p. 219). Esta consecuencia antidemocrática sería igual para el partido comunista y para el líder populista pues en ambos la hegemonía implica la representación de la totalidad social por parte de una de sus partes negando la especificidad de las demás.

En consecuencia, y aunque Laclau no lo viera así, el resultado necesario del ejercicio hegemónico, más si es entendido como un productor de identidades políticas, es necesariamente antidemocrático y no emancipador. Si entendemos que el potencial emancipador del populismo reside en su capacidad para incluir en el sistema político las demandas sociales invisibilizadas o no resueltas, la estrategia hegemónica laclausiana de acción no podría responder a dicho potencial porque no desembocaría en un sistema institucional de respuesta a las mismas, sino en una refundación política totalizante. La pregunta resultante de esto es ¿puede existir el populismo sin hegemonía? Y por tanto ¿es posible un populismo emancipador? Veamos una posible respuesta.

\section{Una nueva topología: posthegemonía y el populismo}

He presentado dos críticas al populismo laclausiano como proyecto emancipador: su incapacidad para institucionalizar el momento de ruptura populista y su uso de la estrategia de la hegemonía de Gramsci incompatible con la diversidad necesaria para la democracia. Ante estas críticas no importa la ideología subyacente al movimiento populista, sea izquierda o derecha en cualquier versión, el resultado será antidemocrático y desinstitucionalizador. En este apartado presento una nueva topología populista que supera la distinción izquierda-derecha tradicionalmente usada, en favor de la clasificación afirmación-transformación adaptada de los trabajos tempranos de Nancy Fraser y del desarrollo del concepto de posthegemonía. Aquí entonces se clasifica el populismo no en función de su articulación de pueblo como sugiere Mouffe (2018) sino por su capacidad democratizante, entiendo esto como la capacidad de incluir sectores sociales excluidos y transformar las instituciones políticas para garantizar una participación plena en los escenarios políticos.

Pese a que la intención política de Laclau no era esta su teorización sobre populismo se muestra débil frente a las críticas antes presentadas y, por tanto, pareciera flaquear como proyecto capaz de construcción democrática posterior a la llegada al poder. El rechazo de la lógica diferencial institucional y su empeño en la construcción hegemónica termina, en la práctica, por mantener demandas sociales insatisfechas que a su vez fortalecen la preservación de su formación del pueblo introduciendo al movimiento en una especie de círculo vicioso de demandas sociales insatisfechas tal como muestra José Luis Villacañas en otro clásico del campo Populismo (2017).

Este escenario nos deja ante una necesidad de complementación teórica. Propongo entonces una alternativa que sin dejar de ser populista implique un fortalecimiento de las instituciones políticas y las condiciones materiales y simbólicas que puedan resolver las demandas sociales aunque implique esto la desarticulación misma del movimiento populista. Propongo entonces una clasificación del populismo que responda a esta necesidad. Por un lado, existe un populismo que depende de la articulación hegemónica y los problemas que la misma implica para un proyecto emancipador y por otro, un populismo no hegemónico que sirve más como transición política para la consolidación de movimientos emancipadores que de vehículo mismo de poder.

Para comprender las características de ambas versiones del populismo propongo revisar la distinción afirmación-transformación que presentó Nancy Fraser (1997) para ilustrar la inoperancia de la acción afirmativa como respuesta a la injusticia social:

Con soluciones afirmativas a la injusticia, me refiero a aquellas soluciones dirigidas a corregir los resultados inequitativos de los acuerdos sociales, sin afectar el marco general que los origina. Por soluciones transformativas, por el contrario, entiendo aquellas soluciones dirigidas a corregir los resultados inequitativos, precisamente mediante la reestructuración del marco general implícito que los origina. El punto esencial del contraste es: resultados finales versus procesos que los generan, no el cambio gradual versus el apocalíptico (Fraser, 1997, p. 38).

En concreto, para Fraser una política afirmativa es aquella que intenta corregir una injusticia o demanda social insatisfecha y lo hace sin alterar el origen de dicha demanda. Por el contrario, una política transformativa es aquella que se dedica a alterar el origen estructural de la injusticia o demanda social insatisfecha para evitar que esta se produzca en el futuro. En el mismo sentido, podemos hablar de populismo afirmativo y populismo 
transformativo en función de su intención política de respuesta a las demandas sociales insatisfechas que lo originaron y, otras que puedan agregarse posteriormente. Se hace notable que una actitud frente a la solución de las demandas sociales insatisfechas impacta la estabilidad de la formación hegemónica y en su pretensión de representación de la totalidad social. Por tanto, postular esta topología requiere una doble perspectiva: la actitud frente a la solución de demandas sociales y el grado de compromiso con la estrategia hegemónica.

En general, llamaremos populismo afirmativo a aquel que mantiene las instituciones políticas debilitadas y por tanto las demandas sociales insatisfechas para sostener en el tiempo la formación del sujeto popular en antagonismo con un afuera constitutivo: la oligarquía, la unión europea, los inmigrantes, etc. Por su parte, llamaremos populismo transformador al que existe para desaparecer, es decir, al que tiene por objetivo la toma del poder político para democratizar las instituciones políticas. Estas permiten alterar el origen de las demandas sociales y con esto desarticular su base social, con poco o nulo compromiso con la estrategia de la hegemonía laclausiana. En efecto, este último tipo de populismo es aquel que existe solo como transición a otro momento político que bien podríamos llamar normal pero que implica la transformación las condiciones materiales y simbólicas de los grupos e individuos que conforman su base social y, por tanto, impulsa la participación política de la misma en el escenario posterior.

He propuesto una distinción muy simple que se complejiza en función de su relación con la estrategia hegemónica. Esta relación es central pues mientras el populismo se mantenga fiel a la estrategia de la hegemonía no habría cabida a la institucionalización democrática posterior o al menos no en una versión realmente pluralista. En esta medida, sostengo que un populismo afirmativo es necesariamente hegemónico pues, de acuerdo con su actitud frente a la solución de las demandas sociales, ha mostrado que su finalidad es la representación de la totalidad social anulando los antagonismos presentes al interior de la sociedad misma. Un populismo con estas características necesitará tarde o temprano recurrir al antagonismo con un afuera constitutivo foráneo que reemplace las luchas ideológicas internas cuando el proyecto hegemónico se haya consolidado. Por eso, tanto Trump como Chávez recurrieron al enemigo externo, los inmigrantes para el primero y el imperialismo norteamericano para el segundo, cuando vieron sus posiciones políticas lo suficientemente fuertes al interior de sus sociedades.

Un populismo transformativo debe superar el uso de la hegemonía como estrategia o al menos debe considerarla como un elemento de acción política muy limitado. Esto debido a que el telos de un populismo así, es su misma desarticulación debido a que su éxito consistiría en la solución de las demandas sociales que lo originaron. El resultado de una finalidad tal para un movimiento populista es su abandono de la aspiración de representación de la totalidad social a favor de la inclusión en el sistema institucional, transformado de paso por los nuevos participantes, de sectores que no estaban siendo representados ni beneficiados, o incluso eran perjudicados por el mismo.

En la recuperación de Laclau y Mouffe, el concepto de hegemonía es entendido como el consenso que logra la clase dominante con las clases subalternas para la dirección política de una sociedad convirtiéndose también en "una práctica que produce sujetos" (Mouffe, 2015). En La razón populista (2009), Laclau empieza a considerar que la lucha popular es diferente de la lucha diferencial pues esta última responde al sostenimiento del orden institucional establecido. Así, entiende Laclau que la división social que implica la creación de un bloque histórico debe ser permanente y no circunstancial. En otras palabras, Laclau avanza la hegemonía hacia un populismo que mantiene la conflictividad social de forma permanente, al tiempo que una clase popular asume la identidad de la totalidad de la sociedad.

El problema es evidente para un populismo con aspiraciones emancipadoras. No se puede emancipar un pueblo sometiendo sus partes a las lógicas de una particularidad, pues no se concreta la transformación del plebs en el populus. Además, el sujeto popular resultante de este populismo es un sujeto dominado, pues ha sido creado a través de una resignificación del campo semántico y, por tanto, entiende el mundo a través de ella y no de sus propias coordenadas de sentido. Así, este populismo hegemónico o afirmativo no ha sido creado para resolver las demandas sociales sino para mantenerse como bloque histórico y, en consecuencia, para reemplazar una dominación por otra.

Contra el populismo hegemónico, aquí llamado afirmativo, ha surgido una propuesta teórica que se propone revisar la posibilidad de un populismo sin hegemonía, un populismo marrano como lo llamaría Alberto Moreiras (2020). La propuesta de Moreiras consiste en un populismo de mínimos que abandone toda pretensión hegemónica y que amplíe los espacios de participación democrática entendida como la permanente negociación entre opuestos. Para explicitar este desarrollo, voy a esbozar primero el concepto de posthegemonía y posteriormente, mostraré cómo Moreiras adapta dicho concepto en su propuesta de un populismo marrano .

La teoría de la hegemonía y la de posthegemonía se separan radicalmente, aunque mantengan lazos de complementariedad: mientras para la primera el pueblo, la hegemonía, el sujeto popular se constituye discursivamente al interior de la sociedad, para la segunda, el sujeto colectivo, el pueblo, existe independientemente de los usos discursivos dominantes y, por el contrario, se resiste a los mismos. Por supuesto, esta separación puede entenderse en términos temporales pues existirían momentos que requieran articulación hegemónica débil para sortear crisis políticas y sociales profundas pero esa articulación, en la 
perspectiva posthegemónica, debe mantenerse débil y no sostenerse una vez se haya resuelto la crisis. En un intento de clarificación, Moreiras ha condensado el concepto de posthegemonía y su aplicabilidad política así:

Posthegemony proposes a practice of general dissensus, that is, a refusal of hegemonic intrusion in singular life (whether personal or collective), wherever it comes from. This results, or should result, in political practice understood as the permanent negotiation of conflict on ever pragmatic, that is, tactical grounds, and in view of whatever is possible at every given conjuncture, and at every step in the conjuncture. [...] Posthegemony is an operational indicator for political practice, not a political doctrine. Its strategy is the accomplishment of democratic equality both now and for the future, but tactically it prescribes nothing beyond the permanent use of thought at the service of a (pragmatic) refusal of domination, formally defined as hegemonic intrusion in singular life. (Moreiras, 2020). ${ }^{3}$

Esta propuesta de una estrategia posthegemónica toma distancia de la hegemonía en tanto renuncia a la pretensión de representación de la totalidad social y, por el contrario, reconoce la imposibilidad de esto. Además, realza el ejercicio de la política como negociación entre adversarios, evitando caer en la pospolítica, a través de un proceso de institucionalización de las dinámicas de negociación. Una posición tal posibilita la existencia de un populismo transformativo pues compatibiliza la estrategia de acción política con la ruta autodestructiva que debe seguir un populismo tal. No obstante, hasta aquí, la posthegemonía no es más que un ideal democratizante del accionar político que no se dilucida aún como estrategia de acción populista. Es claro para Moreiras que el pueblo no es el resultado de una particularidad convertida en universalidad, por el contrario, el pueblo es constitutivo del populismo y no su resultado, es la plebs. No es una identidad política formada por un uso común de significantes flotantes es una no-identidad donde se encuentran todos aquellos que están por fuera de la participación democrática pero que se movilizan en favor de su inclusión expresando así un compromiso con la ampliación de la libertad republicana. Como bien afirma Moreiras: "Sin movilización puede haber política, pero no hay política populista" (2016, p. 11).

Este pensador reconoce que no es posible eludir dos resultados de la organización de un pueblo movilizado pero este entendimiento de la verticalización del movimiento y del antagonismo deben considerarse entonces como posthegemónicos, pues no pretenden la producción de un nuevo sujeto. Mientras que el sujeto al que aspira la teoría de la hegemonía está preconfigurado por las dinámicas de la política y todas las esferas de su vida mantienen una relación con el ejercicio político; similar a la propuesta de club de la vida moral de Gramsci, el sujeto en el populismo posthegemónico solo compromete una esfera de su vida o una parte de su tiempo en una coyuntura política muy específica.

Aquí Moreiras describe, sin que esta sea su topología, una cara del populismo transformativo, pues considera que el movimiento populista existe en una coyuntura y tiende a su desaparición en la medida que pueda afrontar los motivos que la produjeron en primera instancia. Si complementamos esta reflexión con la idea de transformación de Fraser, que describimos al inicio del apartado, encontraremos un camino populista hacia la profundización de la democracia y la libertad republicana, entendida como no-dominación. Un populismo construido para resolver las demandas sociales de quienes lo configuran en la lucha antagónica por la institucionalidad estatal. Pero esta clasificación, más el desarrollo de posthegemonía de Moreiras, parecen inconclusos si no se orienta una posible salida un telos del proyecto político. No obstante, parece existir una salida a este faltante de la mano de pensadores y pensadoras de Latinoamérica y España.

En las nuevas vertientes del pensamiento de izquierda se propone en una lectura republicana de Maquiavelo, que pone de relieve la necesidad de condiciones materiales para la participación política y la solución a las necesidades de las clases bajas; al tiempo que usa el conflicto interno presente en toda sociedad para la creación y mantenimiento de instituciones republicanas que estén al servicio de todos y todas. Las tendencias son dos: el populismo republicano (Cadahia y Coronel, 2018; Mouffe 2018; Fernández, 2016) y el republicanismo con transición populista (Villacañas, 2017). Las primeras postulan la necesidad de pensar la república como un instrumento para la realización de las necesidades del pueblo a partir de instituciones republicanas que se fundan a partir de movimientos populistas. La segunda postura considera que si bien el populismo tiene capacidad estratégica de toma del poder finalmente debe convertirse en un republicanismo cívico que abandone las formas populistas para dar paso a un espacio de fortalecimiento institucional democrático. En cualquier caso, ambas posturas abogan por usar el populismo como un elemento que derive en una mayor apertura democrática de las sociedades. No obstante, y este es el punto en que me aparto de ambos entendimientos, no existe una toma de distancia con el uso de hegemonía de Laclau que como vimos tiene implicaciones en la posibilidad de democratización a partir de construcciones populistas.

La posthegemonía propone una práctica de disenso generalizado, esto es, un rechazo de la intrusión hegemónica en la vida singular (ya sea personal o colectiva), venga de donde venga. Esto resulta, o debería resultar, en una práctica política entendida como la permanente negociación del conflicto sobre bases pragmáticas, es decir, tácticas, y en vista de lo que sea posible en cada coyuntura y en cada paso de la coyuntura. [...] posthegemonía es un indicador operacional de la práctica política, no una doctrina política. Su estrategia es el logro de la igualdad democrática ahora y en el futuro, pero tácticamente no prescribe nada más allá del permanente uso del pensamiento al servicio de un (pragmático) rechazo de la dominación, formalmente definida como intrusión hegemónica en la vida singular. 
Pese a las debilidades, estos desarrollos recientes nos muestran cómo el populismo, antes considerado una propuesta contraria a las instituciones republicanas, debido en parte al rechazo de Laclau a la lógica diferencial, tiene posibilidades de convertirse en proyectos democratizantes que superen el populismo mismo. La clave de esta posibilidad vino sin duda de los escritos de los argentinos Eduardo Rinesi y Matías Muraca (2009), quienes leyendo el republicanismo que expone Maquiavelo en los Discursos sobre la primera década de Tito Livio (2011) encontraron el punto de encuentro clave entre el populismo y el republicanismo. Según estos autores, Maquiavelo confiere al conflicto de clases la potencialidad de crear instituciones republicanas que respondan a las necesidades de cada clase construyendo un único cuerpo popular (populus) que es base de la república. Los argentinos opinan que es precisamente en la dualidad conflictivismo-consensualismo, presente en todo populismo y en el republicanismo de Maquiavelo, donde se pueden hallar puntos de encuentro entre ambas tradiciones. Es decir, que el conflictivismo propio del populismo puede configurar un populismo transformador que posibilite la transición a un republicanismo emancipador.

En su análisis de la creación de la república romana, Maquiavelo distingue tres momentos importantes. En primer lugar, desde Rómulo hasta el último de los reyes, se instituyeron leyes que garantizaban la libertad, pero excluían la aristocracia y al pueblo. Esta exclusión era peligrosa para la unidad del Estado, pues podría exacerbar rebeliones en las de la oligarquía y del pueblo (plebs). Una vez caída la monarquía, desapareció la figura del rey que fue reemplazada por la de Cónsul que cogobernaba con el senado. Ahora se incluía a la aristocracia en la dirección política, brindando más estabilidad a la república que ya era un sistema mixto con pesos y contrapesos. Sin embargo, la exclusión del pueblo, entendido como plebs, era aún más peligrosa, pues la mayoría de los romanos eran parte de este grupo y ahora eran los únicos excluidos del sistema de gobierno. Para contrarrestar el peligro de rebelión del pueblo, se crearon los tribunales del pueblo, que incluían el elemento popular que estaba ausente en el gobierno mixto de Roma (Maquiavelo, 2011). Los tribunos del pueblo o tribunos plebeyos eran magistraturas escogidas por la asamblea plebeya con la intención de hacer contrapeso a los poderes de los aristócratas (Patricios). Según Gabernet y Moler:

Su función esencial es proteger a la plebe individualmente o como clase, contra eventuales arbitrariedades de los magistrados patricios. Para el ejercicio de este auxilium se valían de la intercessio, del derecho de veto con el que pueden detener e impedir las órdenes, los decretos, las levas del Cónsul, las decisiones del Senado, las propuestas de ley, las elecciones, y las convocatorias a comicios para cualquier fin, así como todo acto de los poderes públicos, hasta el extremo de poder detener toda la maquinaria de Estado. Esta actividad la ejerce por petición del ciudadano o por su propia iniciativa (1992, p. 55).

Esta separación de poderes que permitía los contrapesos en todas las clases tramita el conflicto de clases a partir de la creación de instituciones republicanas que salvaguardan los intereses de todos sin eliminar el conflicto mismo que ahora se tramita institucionalmente. Es así como el modelo de república mixto romano incluye elementos de la monarquía, la aristocracia y la democracia. Y es precisamente el conflicto en el campo de lo común a todos, el pueblo (populus) como la totalidad de los ciudadanos, donde se originan las leyes y las instituciones de la república por un movimiento constante entre conflicto y consenso.

Este camino republicano pareciera ser aceptado por una gran parte de los y las pensadoras que han avanzado en la teorización y consolidación del populismo como un proyecto que supera al mismo Laclau. Sin embargo, la transición del populismo al republicanismo o su hibridación, según la propuesta, se muestra aún débil pues la crítica sobre los efectos debilitadores de la institucionalidad democrática y la aspiración de representación de la totalidad que se dirigen a Laclau parecieran trasladarse con facilidad a estos desarrollos. No obstante, el horizonte aquí propuesto supera esta dificultad al considerar que el populismo podría configurar un dispositivo político de transición, emancipación y democratización en tanto se desprenda del entendimiento laclausiano de la hegemonía que hace indistinguible la política del populismo y de la hegemonía misma. De esta manera, un populismo que no consolide una hegemonía sería capaz de tomar una dirección republicana.

\section{Conclusiones}

Hemos presentado la obra de Ernesto Laclau como un desarrollo teórico excepcional en la teorización de un concepto que genera tantas resistencias como el populismo. No obstante, se ha mostrado cómo la misma articulación teórica entre populismo y hegemonía termina reforzando los temores que el populismo genera en la opinión general: su tendencia a la desinstitucionalización y al autoritarismo. Muchos autores, Laclau incluido, han intentado argumentar que estas dos características negativas del populismo son superadas al conjugar el populismo con la ideología. Si el populismo es de izquierda, entonces pareciera tender a la democratización y si es de derecha, al autoritarismo. Como se argumentó aquí, ambas perspectivas ideológicas sin una revisión sobre el populismo mismo podrían conducir por caminos similares con discursos diferentes.

En respuesta a esta dificultad de Laclau para responder a las críticas sin abandonar la idea de la hegemonía, se ha propuesta reconceptualizar las diferencias del populismo en un eje distinto a la posición ideológica, sin 
perderla por completo, en el eje afirmación-transformación. Aquí, el populismo afirmativo encarna al que usa la hegemonía como elemento central de articulación social y tiene una escasa respuesta institucional a las demandas sociales insatisfechas. Por su parte, llamamos populismo transformativo a una práctica populista desprendida de la hegemonía, o por lo menos con un uso muy limitado de la misma, que tiene por horizonte la solución de las demandas sociales insatisfechas a través del fortalecimiento republicano del Estado con perspectiva plebeya, desde abajo.

Pese a ser una propuesta de clasificación que podría aparentar relativa superficialidad, la discusión propuesta toca la esencia política que Laclau asignó a la política y a la política populista. Además, crea un puente de comunicación entre dos corrientes de pensamiento que en la estela de Laclau han empezado a desarrollar complementos y correcciones a su teoría. Por tanto, esta clasificación permite teorizar sobre el populismo como instrumento político empleable en procesos políticos emancipatorios que deriven en proyecto republicanos democráticos comprometidos con la solución a las demandas sociales insatisfechas, el fortalecimiento de las instituciones políticas democráticas y la libertad como no dominación.

\section{Bibliografía}

Aboy, Gerardo (2010). Las dos caras de Jano: acerca de la compleja relación entre populismo e instituciones políticas. Pensamiento plural, (7), 21-40.

Arditi, Benjamín (2010). ¿Populismo es hegemonía, es política? La teoría del populismo de Ernesto Laclau. Constellations, 17(2), 488-497. https://doi.org/10.1111/j.1467-8675.2010.00587.x

Bertomeu, María (2005). Republicanismo y propiedad. Sin Permiso, 1-7. Recuperado de http://www.sinpermiso.info/ textos/republicanismo-y-propiedad

Borón, Atilio. (2000). Tras el búho de Minerva: mercado contra democracia en el capitalismo de fin de siglo. Fondo de Cultura Económica.

Cadahia, Luciana y Coronel, Valeria (2018). Populismo republicano: más allá de «Estado versus pueblo». Nueva sociedad, (273), 72-82.

Cadahia, Luciana (2019). El círculo mágico del Estado. Lengua de Trapo.

De Ípola, Emilio (2009). La última utopía. Reflexiones sobre la teoría del populismo de Ernesto Laclau. En C. Hilb (Comp.), El político y el científico. Ensayos en homenaje a Juan Carlos Portantiero (pp. 197-220). Siglo Veintiuno.

Fernández Liria, Carlos (2016). En defensa del populismo. Los libros de la Catarata.

Fraser, Nancy (1997). Iustitia Interrupta: reflexiones críticas desde la posición "postsocialista" (Magdalena Holguín e Isabel Cristina Jaramillo, Trad.). Siglo del Hombre.

Fraser, Nancy (18-02-18). La alternativa es el populismo progresista, que intenta combinar la protección social con la emancipación. CTXT. https://ctxt.es/es/20180214/Politica/17894/que-hacer-documental-nancy-fraser-feminismoneoliberalismo.htm

Gavernet, Haroldo y Moler, Antonio (1992). El Romano, la tierra, las armas. Lex.

Guariglia, Osvaldo (2011). La Democracia en América Latina: la alternativa entre populismo y democracia deliberativa. Isegoría, (44), 57-72. https://doi.org/10.3989/isegoria.2011.i44.719

Instituto 25M. (23 de julio de 2015). ¿Qué es política? Intervención de Chantal Mouffe. [Video]. YouTube. https://www. youtube.com/watch?v=e1gDuIAB5Og

Krauze, Enrique (2018). El pueblo soy yo. Debate.

Laclau, Ernesto (1996). Emancipación y diferencia. Ariel.

Laclau, Ernesto (2009). La razón populista (Soledad Laclau, Trad.). Fondo de Cultura Económica.

Laclau, Ernesto (2009b). Populismo: ¿qué nos dice el nombre? En El populismo como espejo de la democracia (pp. 5170). Fondo de Cultura Económica.

Laclau, Ernesto y Mouffe, Chantal (2004). Hegemonía y estrategia socialista, hacia una radicalización de la democracia. FCE.

Maquiavelo, Nicolás (2011). Discursos sobre la primera década de Tito Livio. En Maquiavelo: Obras completas (pp, 245-634). Gredos.

Mazzolini, Samuele (2020). Populism is not hegemony: Towards a re-gramscianization of Ernesto Laclau [El populismo no es hegemonía: hacia una regramscianización de Ernesto Laclau]. Theory \& Event, 23(3), 765-786.

Mouffe, Chantal (2018). For a left populism [Por un populismo de izquierda]. Verso.

Moreiras, Alberto (17-07-2020). On hegemonic intrusion [Sobre la intrusión hegemónica]. Infraphilosophy. https:// infraphilosophy.com/2020/07/17/on-hegemonic-intrusion-an-attempt-at-clarification/

Moreiras, Alberto (2016). Sobre populismo y política. Hacia un populismo marrano. Política común, 10. https://doi. org/10.3998/pc.12322227.0010.011

Panizza, Francisco (2008). Fisuras entre populismo y democracia en América Latina. Stockholm review of Latin American Studies, 3, 81-93.

Retamozo, Martín. (2011). Tras las huellas de Hegemón. Utopía y praxis latinoamericana, 16. 39-57. 
Rinesi, Eduardo y Muraca, Matías (2009). Populismo y República: Algunos apuntes sobre un debate actual. En E. Rinesi,

G. Vommaro, M. Muraca (Eds), Si este no es el pueblo (pp. 58-74). Universidad Nacional General Sarmiento.

Villacañas Berlanga, José Luis. (2017). Populismo. La Huerta Grande. 